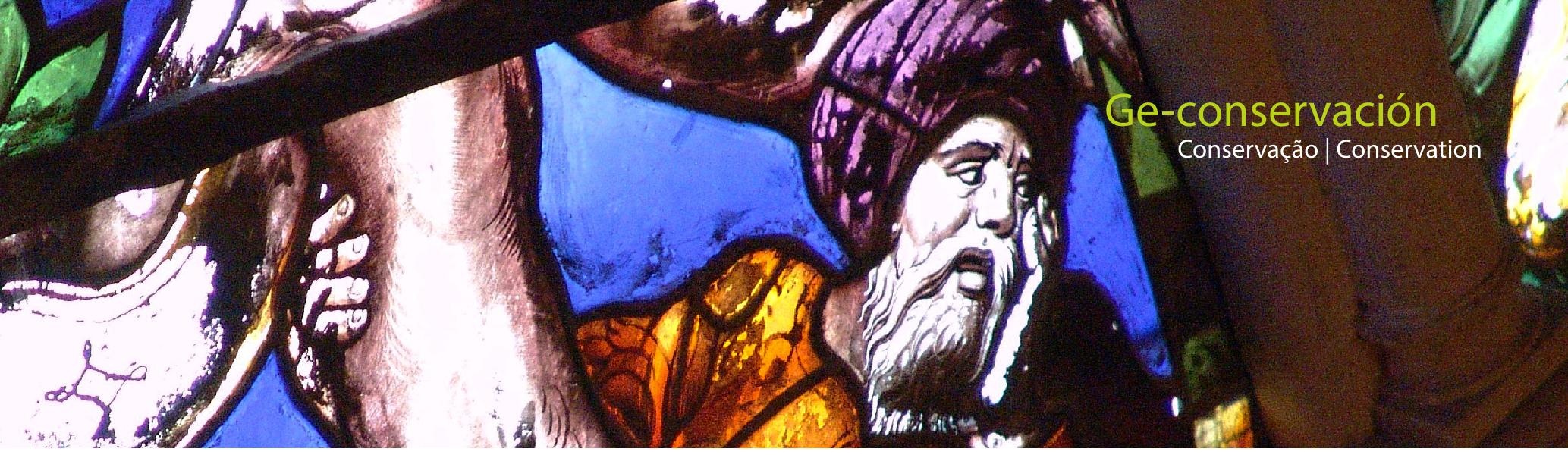

\title{
Reflexiones sobre la necesidad de crear estudios superiores en conservación y restauración de vidrieras en España
}

\author{
Fernando Cortés Pizano
}

Resumen: El presente artículo intenta poner de manifiesto la gran necesidad que existe en España de crear estudios superiores en conservación y restauración de vidrieras, así como la importancia que desempeñaría el aprendizaje y dominio del oficio tradicional de vidriero en dichos estudios. En efecto, las habilidades manuales y aspectos técnicos empleados tanto en la creación como en la conservación y restauración de vidrieras están íntimamente relacionados, hasta el punto de que sería difícil entender los unos sin los otros en la formación de futuros conservadores-restauradores. Es pues de la mayor importancia que cualquier intento de crear unos estudios superiores en esta disciplina no descuide la importancia de este aspecto.

Palabras clave: vidrieras, vidrieros, conservación, restauración, oficio, tradición, estudios superiores

\section{Reflections on the need to create higher studies in conservation and restoration of stained glass in Spain}

Abstract: This article tries to highlight the great need that exists in Spain to create higher education studies on stained glass conservation and restoration, as well as the importance that the learning and mastering the traditional glazier's crafts would play in these studies. Indeed, the manual skills and technical aspects used both in the creation and in the conservation and restoration of stained glass windows are intimately related, to the extent that it would be difficult to understand one without the other in the training of future conservators-restorers. It is therefore of the greatest importance that any attempt to create higher education studies on this discipline do not neglect the importance of this aspect.

Keyword: stained glass, glaziers, conservation, restoration, craft, tradition, higher education

\section{Reflexões sobre a necessidade de criar estudos superiores em conservação e restauro de vitrais na Espanha}

Resumo: Este artigo tenta destacar a grande necessidade existente na Espanha de criar estudos superiores em conservação e restauro de vitrais, bem como a importância que a aprendizagem e o domínio do trabalho do vidreiro tradicional teriam nesses estudos. De facto, as habilidades manuais e os aspetos técnicos usados, tanto na criação quanto na conservação e restauro de vitrais, estão intimamente relacionados, a ponto de que seria difícil entender uns sem os outros na formação de futuros conservadores-restauradores. Portanto, é da maior importância que qualquer tentativa de criar ensino superior nesta disciplina não negligencie a importância deste aspeto.

Palavras-chave: vitrais, vidreiros, conservação, restauro, comércio, tradição, ensino superior 


\section{La sorprendente supervivencia de un arte frágil}

Las vidrieras tradicionales, esa combinación única y magistral de vidrios planos sustentados por perfiles de plomo soldados con estaño, existen desde hace más de mil años y siguen fascinando a cada nueva generación. Sus orígenes están estrechamente vinculados a la arquitectura cristiana de la Alta Edad Media en Europa, con muy posibles influencias del arte islámico. Estas obras han pasado por una gran diversidad de estilos y vicisitudes, habiendo conocido una época de esplendor entre los siglos XII y XVI, una etapa de relativa decadencia y pérdida de oficio en los siglos XVII y XVIII, una recuperación a partir de mediados del siglo XIX, seguida de un periodo de experimentación con nuevas técnicas y materiales desde finales del siglo XIX y finalmente, a partir de la Segunda Guerra Mundial, una segunda etapa de renovación que perdura hasta nuestros días.

Sin embargo, y a pesar de los maravillosos conjuntos de vidrieras conservados en infinidad de edificios repartidos por todo el mundo, el porcentaje de obras que ha llegado hasta nosotros es tan solo una parte pequeña comparada con todas aquellas que han ido desapareciendo a lo largo de los siglos. Y el motivo es bien sencillo. Las vidrieras, funcionando durante años o siglos como hermosas barreras divisorias (de entre 2 y $4 \mathrm{~mm}$ de espesor) entre el exterior y el interior de la gran mayoría de nuestros edificios históricos, son sin duda uno de sus elementos más frágiles y vulnerables. Diversos agentes destructores de la naturaleza (seísmos, incendios, viento, granizo, agua de condensación, microorganismos, etc.), o factores humanos (guerras, iconoclastia, vandalismo, restauraciones poco respetuosas, falta de mantenimiento o cambios de gusto, por mencionar unos pocos), o generalmente una combinación de ambos, han sido tradicionalmente los principales responsables de su progresivo deterioro y desaparición.

Teniendo en cuenta todos estos posibles factores y los mil años de historia que contemplan a este arte, hoy día sigue sorprendiendo que unos materiales tan frágiles hayan podido llegar hasta nosotros, si bien de forma más o menos fragmentaria, habiendo logrado a su vez reinventarse a lo largo de los siglos. En efecto, el arte de la vidriera sigue vivo y además parece gozar de buena salud, a juzgar por la gran cantidad de personas que en la actualidad se dedican a esta especialidad, ya sea como profesionales o como aficionados, como creadores o como conservadoresrestauradores, o más frecuentemente practicando ambas especialidades. Así pues, el hecho de que muchas de las vidrieras más antiguas hayan sobrevivido y podamos seguir admirándolas en la actualidad, es en gran parte también el resultado de siglos de mantenimiento y restauración, con mayor o menor destreza, respeto y cuidado según el periodo histórico o las personas a su cargo [Figura 1].

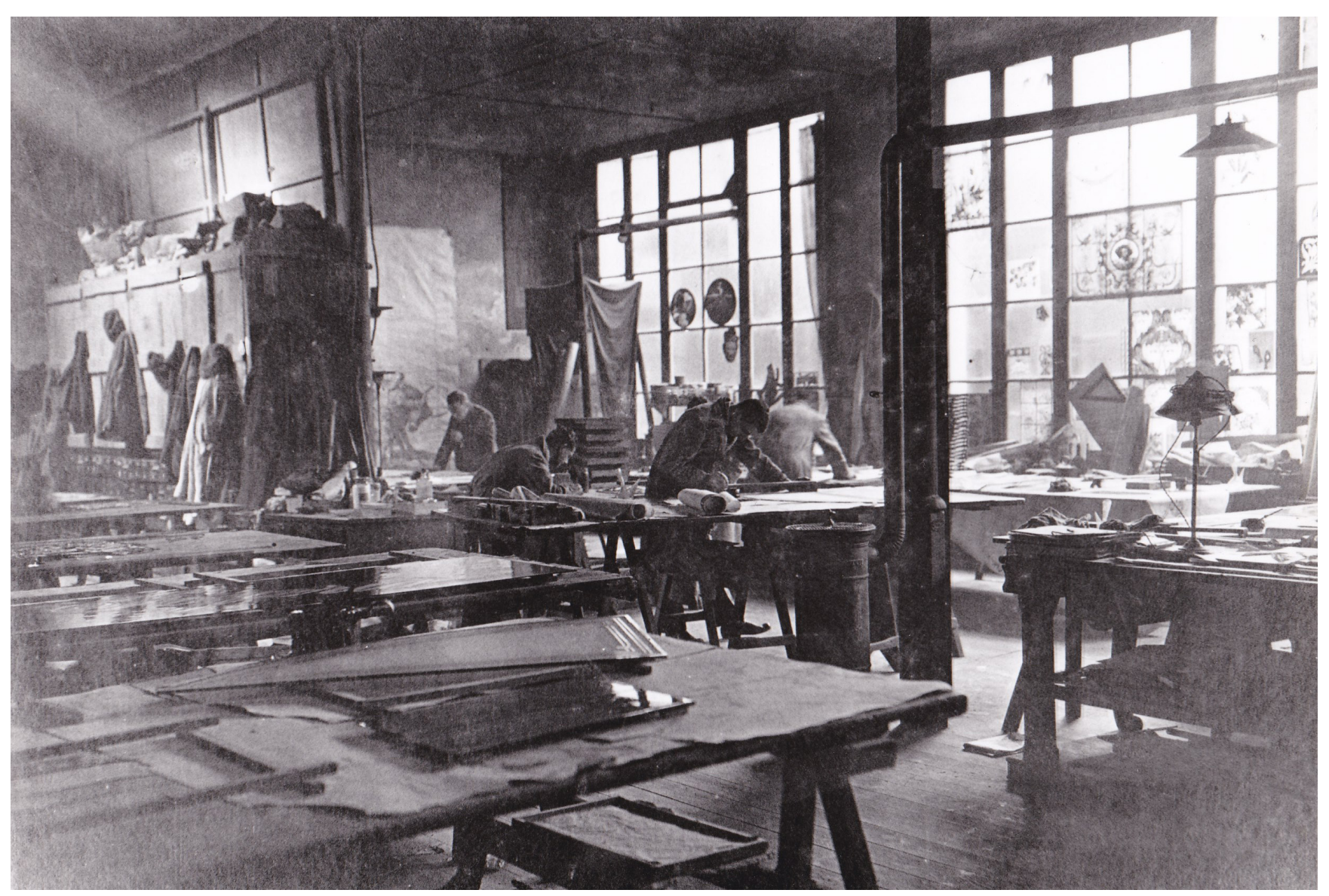

Figura 1.- Fotografía del taller de vidrieras Casa Rigalt i Granell de Barcelona, realizada entre 1920 y 1930 . Imagen del Archivo del Museu del Disseny de Barcelona. Ref. ES ES MDB 3-401-02-02-01-RIG-0607-001 


\section{El carácter funcional o utilitario de las vidrieras y su relación con el edificio}

Las vidrieras cuentan con una ventaja que les ha ayudado en cierta manera a garantizar su supervivencia: su carácter funcional o utilitario. Estas obras son, como ya hemos visto, la piel exterior del edificio y no hemos de olvidar que su principal función es de tipo práctico: cerrar un vano para así impedir el paso de elementos externos (viento, agua, aves, etc.) y garantizar un cierto aislamiento térmico y acústico. Las otras funciones de este arte, sin duda más conocidas, son realmente secundarias desde un punto de vista práctico, como veremos a continuación. Nos referimos a aquellas que le confieren su merecida admiración, como son su carácter estético, decorativo, simbólico, religioso, etc.

Es precisamente su condición de bien inmueble con carácter funcional y utilitario la que convierte en prioritaria la reparación de las vidrieras. Es fácil deducir que, si una vidriera no funciona correctamente como cerramiento, peligra la trasmisión de sus valores estéticos o didácticos. En este sentido, cualquier daño estructural considerable en la obra, como la perdida de vidrios o la rotura o abombamiento de la red de plomo, ha de ser frenado y reparado lo antes posible a fin de evitar el deterioro progresivo de la vidriera o de los paneles afectados y poder garantizar la estanqueidad e iluminación del edificio. Asimismo, no menos importante, una vidriera en mal estado puede presentar un riesgo considerable para la seguridad de las personas y de aquellas otras obras de arte o del mobiliario en sus proximidades. Es por estos motivos que la recuperación de una posible lectura artística o iconográfica interrumpida pasa necesariamente a ocupar un segundo lugar en las prioridades a la hora de plantearnos cualquier intervención sobre este tipo de obras.

Por otro lado, es lógico deducir de todo lo dicho hasta ahora que la conservación y restauración de vidrieras existe desde los mismos orígenes de este arte y que lógicamente han sido y son los mismos artistas vidrieros quienes, casi de forma exclusiva, han estado cualificados para llevar a cabo estas necesarias tareas de mantenimiento o reparación. Esta situación no es exclusiva de las vidrieras y la podemos observar también en otras profesiones $u$ oficios, $y$ de forma más evidente en aquellos aplicados a la arquitectura tradicional, como son los herreros, carpinteros, ceramistas, plomeros, canteros o albañiles, por poner unos cuantos ejemplos. $Y$ es por ese motivo que estos oficios, tan presentes en la mayoría de nuestros edificios históricos, han logrado pervivir, en mejores o peores condiciones, hasta la actualidad. Sin embargo, cuando se descuidan estas tareas de mantenimiento es cuando empezamos a observar un deterioro progresivo en los materiales constructivos o decorativos del edificio, mientras que poco a poco se van perdiendo los oficios asociados a su conservación. Es un hecho constatado que en aquellos periodos en los que el arte de la vidriera gozaba de buena salud y los vidrieros dominaban su oficio, las intervenciones de mantenimiento o de restauración que se realizaban eran frecuentes, respetuosas y de mejor calidad. Por el contrario, en aquellas épocas en las que la vidriera no era tan valorada, su demanda y práctica cayó en desuso y las operaciones de mantenimiento o restauración sencillamente no se llevaron a cabo o fueron más espaciadas o de peor calidad, siendo a menudo practicadas por profesionales de otras especialidades más o menos afines [Figura 2].

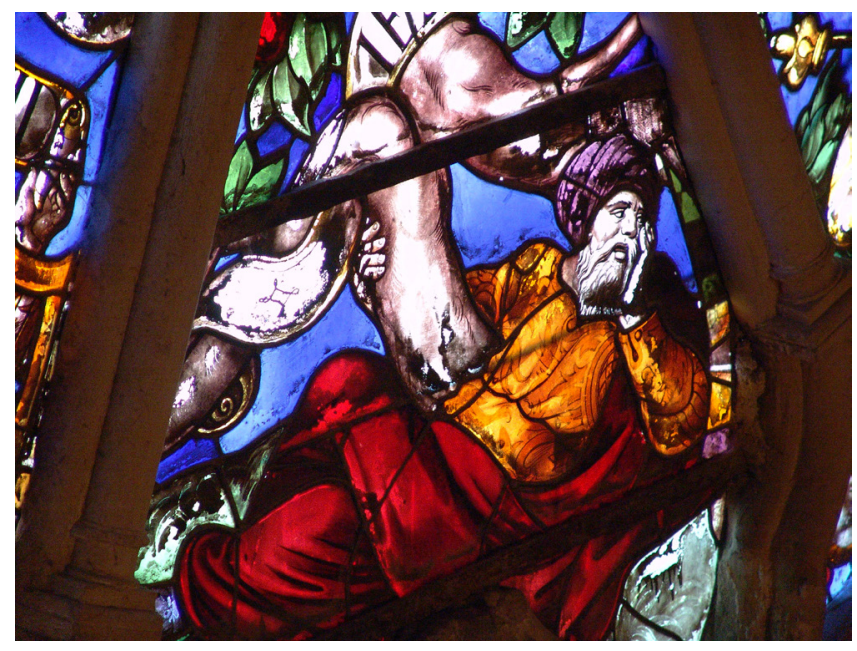

Figura 2.- Figura de Jesé en el rosetón del crucero norte de la Catedral de Cuenca. Giralte de Holanda, 1550. Autor imagen: Fernando Cortes Pizano.

\section{Las consecuencias de la ausencia de una cultura vidriera}

Así pues, si bien el carácter funcional de la vidriera es lo que en gran parte ha mantenido vivo el oficio, este hecho no ha ido lamentablemente acompañado siempre de una apreciación y valoración generalizada de este arte, como ha sucedido en otros países europeos. Y aquí radica en mi opinión el problema principal del abandono y la falta de atención hacia las vidrieras en muchos de nuestros edificios: no existe un conocimiento, y consecuentemente una apreciación, de la cultura vidriera a nivel social, cultural o educativo. Esta falta de valoración se ve reflejada en su escasa divulgación, en su falta de presencia en los museos o en exposiciones, en su ausencia de los programas de investigación y difusión, o en proyectos de intervención, en planes de estudio en conservación y restauración, etc. A esta circunstancia hemos de añadir el hecho de que tradicionalmente las vidrieras han sido percibidas $y$ clasificadas con la cuestionable etiqueta de artes menores, aplicadas o artesanías, lo cual a menudo ha actuado lógicamente en su detrimento.

Por otro lado, el arte y el oficio de la vidriera abarcan un campo muy amplio de conocimientos y destrezas 




Figura 3.- Restos de una vidriera del siglo XVI en la Iglesia San Esteban, en Salamanca. Autor imagen: Fernando Cortes Pizano. 
que incluyen varias disciplinas técnicas, artesanales y artísticas, cuyo dominio suele requerir de muchos años de aprendizaje, trabajo y perfeccionamiento. La dificultad y el tiempo de aprendizaje de los aspectos técnicos de este oficio, han obstaculizado sin duda una mayor difusión de esta profesión y su inclusión en programas de estudio. Por otro lado, los vidrieros se enorgullecen, no sin motivos justificados, de su profesión y de los años de aprendizaje y perfeccionamiento invertidos en la misma. Esta característica se refleja en el hecho de que tradicionalmente el grado de maestro vidriero solo se alcanzaba después de muchos años de duro trabajo y esfuerzo. En cierta manera, esto ha propiciado que los vidrieros sean a menudo vistos, no sin motivos, como un colectivo bastante cerrado, con tendencia al secretismo y poco dado a compartir y divulgar sus conocimientos, ya sea mediante la enseñanza, publicaciones, charlas, etc. [Figura 3].

\section{Sobre las competencias de los diferentes profesionales involucrados en este oficio}

Al plantearnos el futuro de nuestra profesión, no podemos caer en el error de convertir la conservación y restauración de vidrieras en una profesión en la cual los conservadores-restauradores no especializados en este campo dirigen el trabajo de los vidrieros, mientras que estos pasan a desarrollar una tarea auxiliar o de apoyo en el trabajo de los primeros. En mi opinión este enfoque, en ocasiones sugerido, es totalmente erróneo ya que ignora el problema de base: la urgente necesidad de crear estudios superiores en esta especialidad. En efecto, una de las principales críticas que durante años he observado por parte de un sector de los conservadores-restauradores titulados es que los vidrieros no deberían restaurar las vidrieras "sin supervisión", ya que no tienen ni la formación ni los criterios necesarios para esta labor. Estos a menudo sugieren que los proyectos de conservación y restauración en vidrieras deberían estar dirigidos por un conservador-restaurador, quedando los vidrieros subordinados a los primeros para ejecutar la parte manual de la intervención, la cual los primeros no dominan. Los vidrieros por su parte rechazan claramente esta propuesta en base a la carencia de conocimientos necesarios de su oficio y de los materiales de las vidrieras por parte de los primeros. En realidad, los argumentos de ambas partes tienen lógica y sentido, todo depende de cómo los miremos. Si lo pensamos objetivamente, esta situación es comparable en cierta manera a la de los conservadoresrestauradores cuando reivindican su papel frente al del arquitecto encargado de proyectos integrales. $Y$ ya que se ha mencionado a los arquitectos, y para complicar más el panorama expuesto, es importante mencionar que estos, a menudo, tienen también su opinión sobre cómo se deben conservar y restaurar las distintas obras del edifico, entre ellas lógicamente las vidrieras.

Es evidente que es necesario salir de este ciclo vicioso que sin duda no ayuda a resolver la cuestión del estancamiento de las vidrieras. La solución no es sencilla y pasa por buscar puntos comunes de entendimiento y aprender a escucharnos los unos a los otros, manteniendo una actitud dialogante, abierta y sin prejuicios y dejando de lado nuestros egos e ideas preconcebidas. Para ello, lo que a menudo realmente se echa de menos es la ocasión de poder reunirnos todas las partes involucradas en la conservación y restauración de las vidrieras para poder tratar estos temas, buscando soluciones consensuadas que garanticen una adecuada conservación y restauración de este valioso patrimonio [Figura 4].

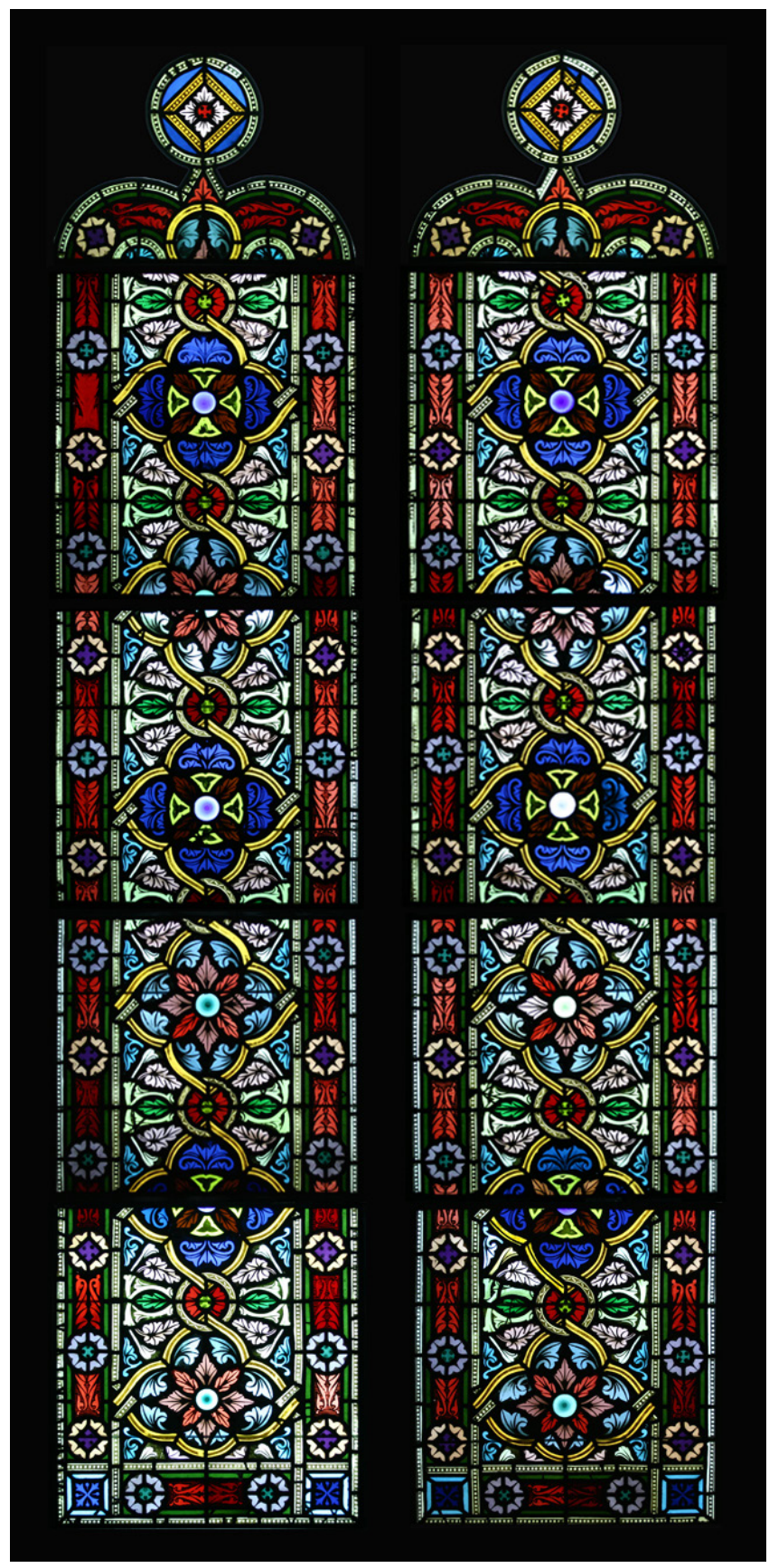

Figura 4.- Vidriera de finales del siglo XIX en la fachada principal de la Catedral de Barcelona. Casa Rigalt i Granell. Autor imagen: Fernando Cortes Pizano. 
La urgente necesidad de crear estudios superiores en conservación y restauración de vidrieras

Tal y como ya hemos apuntado más arriba, no podemos seguir ignorando o aplazando la urgente necesidad de crear, lo antes posible, estudios superiores en esta especialidad, como en su día sucedió con las especialidades de pintura, escultura, documentos, material arqueológico o textil. Pudiera parecer una tarea complicada, pero en aquellos países donde el arte de la vidriera ha sido tradicionalmente más valorado y respetado si han logrado crear estudios universitarios en esta especialidad, situándola a la misma altura que las otras especialidades. Es por ejemplo el caso de las Universidades de Amberes, en Bélgica ${ }^{1}$ y de Erfurt, en Alemania ${ }^{2}$, pioneras desde hace varias décadas en estudios universitarios en conservación y restauración de vidrieras. En el caso de Amberes, los estudios consisten en 3 años de grado y un último año de máster. Asimismo, la Universidad de York, en Inglaterra ${ }^{3}$ también oferta desde 2008 un máster en esta especialidad.

Aparte de los mencionados estudios superiores, también existen diversas asociaciones u organizaciones especializadas en vidrieras. Tal vez el ejemplo más destacado y conocido sea el del CVMA (Corpus Vitrearum Medii (Aevi) ${ }^{4}$, organización internacional creada en los años cincuenta del siglo pasado y dedicada inicialmente al estudio e inventario de las vidrieras más antiguas. Desde los años ochenta se constituyó en cada país miembro un grupo técnico dedicado al estudio sobre aspectos científicos y de conservación-restauración de las vidrieras. Parte importante de su trabajo, desarrollado conjuntamente con el Comité Científico Internacional para la Conservación de Vidrieras de ICOMOS$^{5}$, ha consistido en la organización de reuniones técnicas bianuales y en la redacción de unas Líneas directrices sobre la conservación-

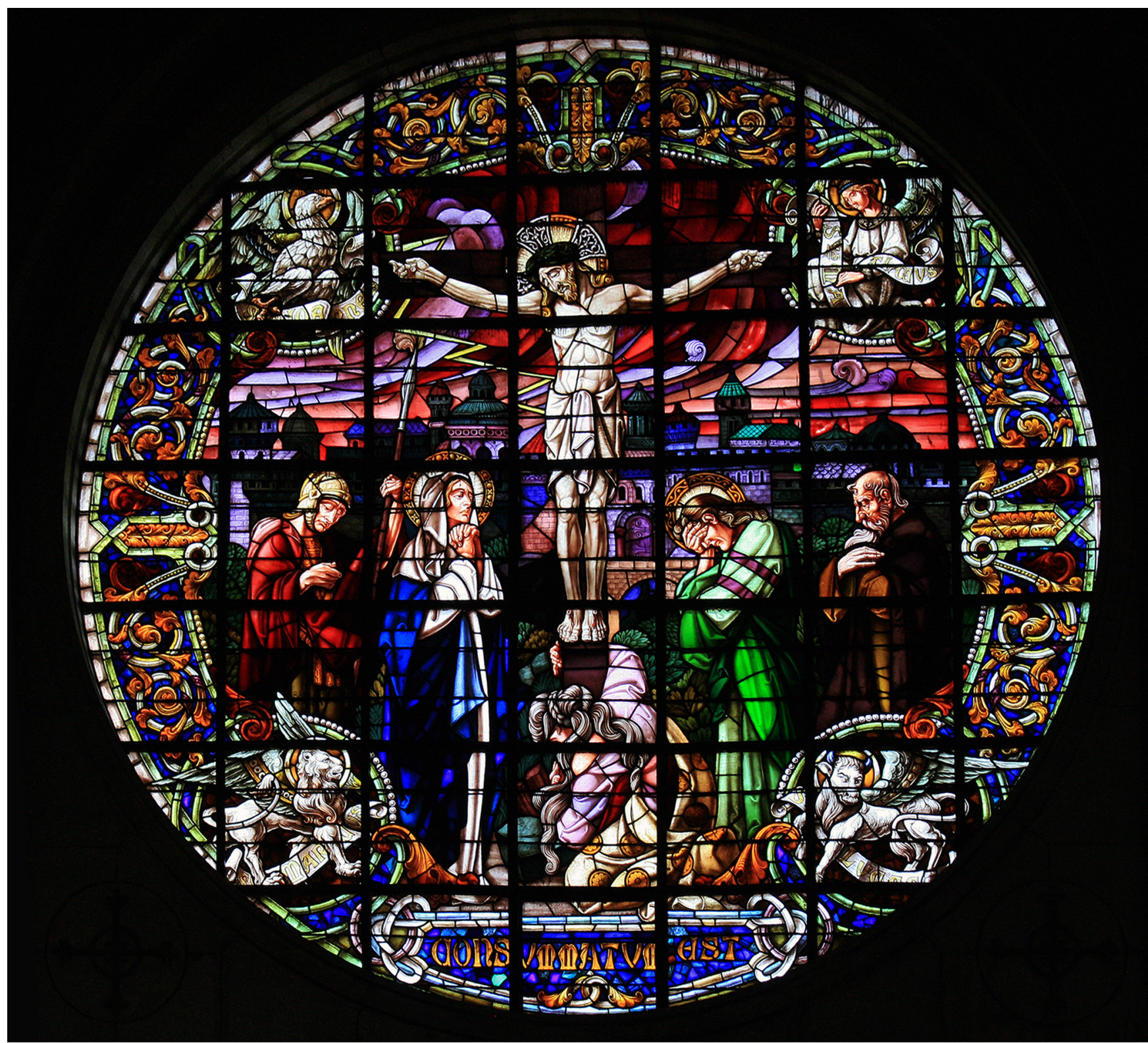

Figura 5.- Vidriera de la Casa Maumejean en la Iglesia del Sagrado Corazón de Jesús, Gijón. Autor imagen: Fernando Cortes Pizano. 
restauración de vidrieras en las reuniones de Ámsterdam en 1989 y Núremberg $2004^{6}$.

Sin embargo, desde las instituciones públicas nunca se ha visto realmente la necesidad o urgencia de crear estudios universitarios en esta especialidad ya que, con mejor o peor técnica o criterio, las vidrieras tradicionalmente las han restaurado los vidrieros. El problema, sin embargo, consiste en que la conservación-restauración de vidrieras es un campo bastante desconocido donde no existen estudios específicos y como consecuencia no resulta sencillo controlar, juzgar o valorar la calidad de las intervenciones realizadas. A menudo, para profesionales de otras disciplinas, pareciera no existir una metodología, normas o criterios específicos para estas intervenciones, ya que en ocasiones los métodos empleados y los resultados obtenidos pueden diferir de aquellos a los que están acostumbrados muchos conservadores-restauradores. En este sentido, no hemos de olvidarnos que las vidrieras, en su particular relación con el edifico y la luz, son un medio que presenta unas peculiaridades que las hace diferentes a otros soportes, y cuya conservación y restauración a menudo exige soluciones diferentes y no por ello menos válidas. En cualquier caso, la realidad es que desde hace ya varias décadas sí existen criterios, normas, estudios superiores e infinidad de publicaciones científicas en esta especialidad, y la gran mayoría de los conservadoresrestauradores de vidrieras conocen y aplican los conceptos de reversibilidad, mínima intervención, discernimiento de las nuevas intervenciones, compatibilidad de los materiales, documentación de la intervención, etc. [Figura 5].

\section{Posibles vías para el establecimiento de estudios superiores}

Después de todos los datos expuestos hasta ahora, bebería resultar evidente la urgente necesidad de crear estudios superiores en esta especialidad en España. Por lo que respecta a las posibilidades prácticas de cómo crear dichos estudios, estos podrían llevarse a cabo bien mediante el establecimiento de una especialidad de vidrieras, equiparable a las ya existentes de pintura, escultura, etc. en las actuales escuelas de restauración, o bien, en su defecto,

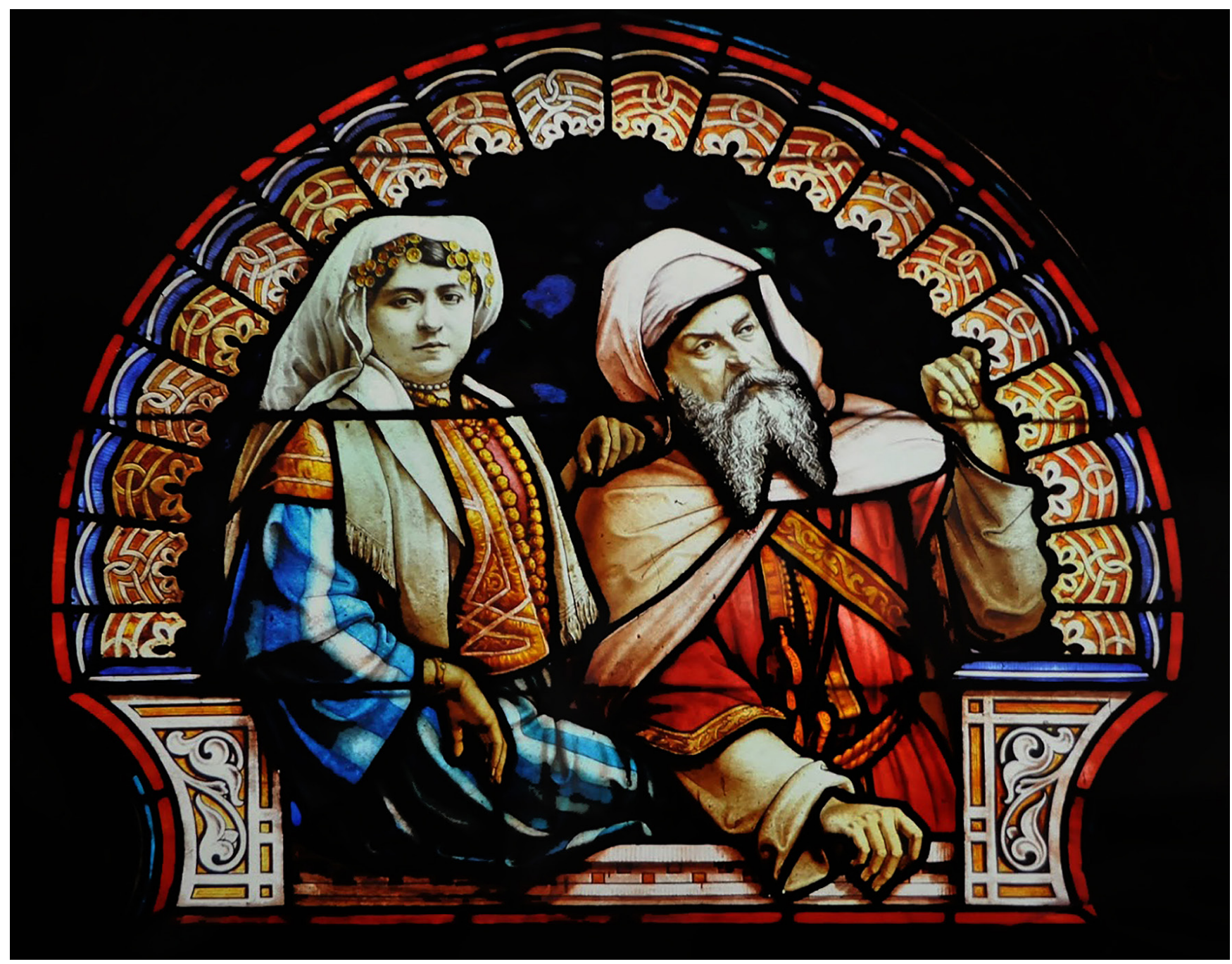

Figura 6.- Procedencia de la imagen: El Blog de Joaquín Medina: http://elblogdejoaquinmedina.blogspot.com/2018/01/diegoperez-director-de-cultura-recibe.html?spref $=\mathrm{fb} \& \mathrm{~m}=1$ 
a través de unas asignaturas sobre esta especialidad en los estudios de conservación-restauración en la Universidad. Sin embargo, personalmente no me parece que el cursar una o unas asignaturas en la Universidad sea la solución para formar especialistas en este campo. En mi opinión, tal y como están en la actualidad configurados los planes de estudios, el crear una especialidad de vidrieras sería sin duda la opción más recomendable para formar profesionales en esta especialidad.

Como ya hemos apuntado anteriormente, estos estudios no deberían descuidar la gran importancia que el aprendizaje de los aspectos artesanales y de oficio desempeñan en la conservación y restauración de vidrieras. Esto significa que el plan de estudios diseñado debería incluir, junto con el resto de asignaturas comunes en los estudios de conservación-restauración, un porcentaje razonable de horas taller. Durante estas clases prácticas se enseñaría el oficio de vidriero, tanto en el taller como en edificios con vidrieras, para así, de esta manera, poder ir introduciendo gradualmente al alumnado en intervenciones de conservación y restauración.

En la actualidad existe una tendencia generalizada a hacer desaparecer las especialidades en favor de un título único en conservación-restauración, relegando las especialidades a la realización de un futuro máster. Esta opción, de llegar a ponerse en práctica, me parecería realmente lamentable, especialmente para el futuro de las vidrieras. Sin embargo, paralelamente, la profesión de los conservadores-restauradores se encuentra en la actualidad en una etapa muy interesante de cambios y exigencias, con un objetivo común muy importante que es el reconocimiento y la regulación de la profesión. Es por ello que estoy personalmente convencido de que es este el momento adecuado para aprovechar el creciente interés en esta especialidad y luchar por la creación de estos estudios.

Como vemos, el laberinto de una futura formación en conservación-restauración de vidrieras históricas no es fácil de recorrer. A pesar de todo es necesario cambiar este panorama y empezar a trabajar codo con codo, conservadores-restauradores, vidrieros, arquitectos e instituciones públicas; proponiendo soluciones viables para que este patrimonio tan frágil y complejo sea debidamente conservado para nuestro disfrute y el de las futuras generaciones. [Figura 6].

\section{Conclusiones}

El patrimonio vidriero de España es indiscutiblemente uno de los más importantes de Europa. Sin embargo, su riqueza y calidad contrasta con la escasa atención y difusión que recibe y a menudo, lamentablemente, con su estado de conservación. La inexistencia de una cultura vidriera en nuestro país está en la base del problema y tiene como resultado la ausencia de estudios específicos sobre esta especialidad y por tanto de conservadores-restauradores especializados. Una de las principales medidas a adoptar es sin duda la creación de estudios superiores universitarios en este campo. Es absolutamente necesario que las autoridades competentes sean conscientes de este problema y que se pongan las medidas necesarias para buscar soluciones.

\section{Notas}

[1] Sobre los estudios en Conservación y Restauración de vidrieras en la Universidad de Amberes en Bélgica: https:// www.uantwerpen.be/nl/studeren/opleidingsaanbod/ bachelor-conservatie-restauratie/profiel/. Consulta: Junio 2019.

[2] Sobre los estudios en Conservación y Restauración de vidrieras en la Universidad de Erfurt, en Alemania: https:// www.fh-erfurt.de/kr/en/studium/studienschwerpunkte/ glasmalerei-und-objekte-aus-glas/?Size $=1$. Consulta: Junio 2019.

[3]. Sobre los estudios en Conservación y Restauración de vidrieras en la Universidad de York, en el Reino Unido: https://www.york.ac.uk/study/postgraduate-taught/ courses/ma-stained-glass-conservation-heritagemanagement/. Consulta: Junio 2019.

[4] Corpus Vitrearum Medii Aevi: http://www. corpusvitrearum.org/. Consulta: Junio 2019.

[5] International Scientific Committee for the Conservation of Stained Glass: http://sgc.Irmh.fr/?Ing=en. Consulta: Junio $\underline{2019}$.

[6] Líneas directrices sobre la conservación-restauración de vidrieras (Núremberg 2004): http://decorativasartesgeiic. blogspot.com/2012/03/. Consulta: Junio 2019.

[7] La Asociación Profesional de Conservadores Restauradores de España (ACRE) ha venido desarrollando un papel importantísimo durante los últimos años en la defensa y reconocimiento de la profesión de los Conservadores-Restauradores.

\section{Bibliografía}

DOCUMENTO DE PAVÍA (1997). "Preservación del Patrimonio Cultural: Hacia un perfil europeo del Conservador-Restaurador". Pavía 18 al 22 de octubre de 1997. http://www.icomos.es/ wp-content/uploads/2017/05/22.documento-pavia1997.pdf. Consulta: Junio 2019.

DOCUMENTO DE VIENA (1998). Conferencia Europea. "Un marco de competencia para conservadores-Restauradores en Europa", Viena 30 de Diciembre al 1 de Noviembre de 1998. http://www.iaph.es/ revistaph/index.php/revistaph/article/view/1177 
DECLARACIÓN DE BOLONIA (1999). “Espacio Europeo de Enseñanza Superior Declaración conjunta de los ministros europeos de enseñanza", Bolonia 19 de Junio de 1999. http:// www.peri.net.ni/pdf/01/Declaraci.pdf. Consulta: Junio 2019.

ENcoRE (2001). "Clarification of conservation/restoration education at university level or recognised equivalent", 3a Asamblea General, Munich, Junio de 2001. http://www.encoreedu.org/ENCoRE-documents/cp.pdf. Consulta: Junio 2019.

E.C.C.O. (2002). “Directrices Profesionales de ECCO. La profesión y su código ético". Bruselas 1 de marzo de 2002. https://ge-iic.com/ files/Cartasydocumentos/2002 directrices \%20profesionales de ecco la profesion y su codigo etico.pdf. Consulta: Junio 2019.

E.C.C.O. (2004). "Competencias necesarias para acceder a la profesión de conservador-restaurador", Bruselas 2 de Abril de 2004. https://asociacion-acre.org/el-conservador-restaurador/ marco-competencias-acceder-la-profesion/. Consulta: Junio 2019.

CAEN, J. (2015). Conservation-Restoration Education in Europe in General, and at the University of Antwerp in Particular, en "Glass is More", 19 de Marzo de 2015:http://www.glassismore.com/ core/content.php?\&option=viewitem\&id=42\&rd=955\&le=120. Consulta: Junio 2019.

\section{Autor/es}



\section{Fernando Cortés Pizano}

fcpcrv@gmail.com

The Cathedral Studios, Canterbury, Reino

Unido (https://www.thecathedralstudios. $\mathrm{com} /$ )

Estudié la carrera de Historia del Arte en la Universidad Complutense de Madrid entre 1984 y 1989 y posteriormente Conservación y Restauración, con especialidad de Vidrieras, en la Real Academia de Bellas Artes de Amberes en Bélgica entre 1994 y 1998, obteniendo el grado de Master. Desde entonces me ha dedicado completamente a la Conservación y Restauración de Vidrieras y mi campo de trabajo abarca tanto la intervencion directa como la docencia, la investigacion, la dirección técnica y el asesoramiento en diferentes proyectos. Desde Enero de 2015 trabajo como restaurador de vidrieras en la Catedral de Canterbury, en Inglaterra.

* La información y opiniones contenidas en el presente artículo son responsabilidad exclusiva de su autor y no reflejan necesariamente las de la empresa donde este trabaja en el momento de su publicación. 